\title{
Optimization of CuW alloy electrodeposition towards high-tungsten content
}

\author{
Pawel Bacal $^{1} \cdot$ Zbigniew Stojek $^{1} \cdot$ Mikolaj Donten $^{1}$
}

Received: 12 April 2016/Revised: 16 July 2016 / Accepted: 19 July 2016 / Published online: 29 July 2016

(C) The Author(s) 2016. This article is published with open access at Springerlink.com

\begin{abstract}
With the help of the factorial design of experiments, optimization of the deposition of the $\mathrm{CuW}$ alloy was successfully done. The important deposition parameters were identified as $\mathrm{pH}$, current density, and - the most important onecopper ion concentration. All of them were examined in their wide ranges. Under optimal conditions, in a citrate bath, with copper ion concentration of $1.0 \mathrm{mM}$, at current density of $-100 \mathrm{~mA} \mathrm{~cm}^{-2}$ and at $\mathrm{pH}$ ca. 8.3 , the alloy layer had the highest tungsten content (circa $30 \mathrm{wt} . \%$ ), satisfactory adhesion and a smooth and crackless morphology. The structure of the electrodeposited alloy can be described as an amorphous solid solution of $\mathrm{Cu}$ in $\mathrm{W}$ with built-in $\mathrm{Cu}$ nanocrystals.
\end{abstract}

Keywords Novel materials - Electrodeposition - Coppertungsten alloy $\cdot$ High-tungsten alloys $\cdot$ Induced codeposition · Fractional factorial design

\section{Introduction}

The demand for new applications and new properties of decorative, protection, and structural materials is the driving force for research and development of new materials [1]. The new materials and methods of their fabrication should be environmentally friendly. Also, the volume of toxic and hazardous

Zbigniew Stojek

stojek@chem.uw.edu.pl

Mikolaj Donten

donten@chem.uw.edu.pl

1 Faculty of Chemistry, University of Warsaw, Pasteura 1, 02-093 Warszawa, Poland wastes and energy losses during their preparation should be maximally limited.

An interesting direction in the development of new metallic materials is amorphous alloys. This "frozen state" or the socalled metallic glass combines a low arrangement of atoms with high homogeneity of their distribution [2]. The lack of structurally ordered regions usually leads to better wear and corrosion resistance, higher toughness, and lower brittleness compared to typical polycrystalline alloys [3].

Preparation of amorphous alloys by electrodeposition can be as good as other methods: chemical- and physical vapor deposition, extremely rapid cooling, mechanical alloying, solid-state reaction, and ion implantation. The big advantages of electrodeposition are its easiness, low cost, and good repeatability [4]. In comparison to the methods mentioned above, electrodeposition is rather a simple technique which does not need a sophisticated toolset or great energy expenditure. It can be used for preparation of tailored, specially designed, and complex-shape objects $[5,6]$.

A special case in amorphous alloys are materials containing significant amounts of either W or Mo. Tens of electrodeposited materials and alloys composed of tungsten and/or molybdenum have been already obtained [7, 8, 9]. Interestingly, the mechanism of their deposition is still not fully understood. The phenomenon of electrodeposition of W or Mo only simultaneously with an iron-group metal $(\mathrm{Ni}, \mathrm{Fe}$, and $\mathrm{Co}$ ) was named the "induced codeposition" by Brenner in the early 1960s [10]. The induced codeposition has been investigated for decades, but none of the conclusions is fully convincing [7, $11,12]$.

Galvanic alloys of tungsten or molybdenum have a variety of applications usually as protective coverages, and as structural materials $[4,13]$. These alloys can be electrodeposited from citrate baths which are known for their low toxicity and long-time usage. In our previous work, we presented a way of 
successful codeposition of tungsten with copper, a metal that does not belong to the iron group [14]. The mechanism of deposition of that material may differ from those postulated for the FeW, NiW, and CoW systems because tungsten and copper do not form thermodynamically stabile homogenous binary phases [15].

Recently, the number of announcements reporting on electrodeposition of tungsten and molybdenum with transition metals other than the iron-group metals [16-18] is growing. Our results indubitably proved that a CuW alloy can be obtained by simultaneous electroreduction and deposition of tungsten with copper. Here, we decided to present a simple and effective method allowing the effective optimization of the plating process. The aim of the investigations was to obtain compact, well adhesive, smooth layers of $\mathrm{CuW}$ alloy containing the highest possible percentage of tungsten. Up to date, the described in the literature attempts to electrodeposit the $\mathrm{CuW}$ alloys are rare $[19,20]$ and in our opinion were not successful in respect to the satisfactory morphology and high tungsten content.

In the present work on electrodeposition of binary $\mathrm{CuW}$ alloys, the experience gained in deposition of binary $\mathrm{Ni}$-, Fe-, and Co-W alloys has been used [21-25]. Basing on that information, the potentially crucial, for this process, parameters were chosen. The performed measurements were preceded by careful analysis of the experimental task. Even after a substantial reduction of number of examined parameters, the number of single plating experiments, necessary for the complete optimization of the process, was high. Thus, it was essential to further reduce the number of planned experiments. We turned to the method of statistical design of experiment. The most promising theoretical combinations of the parameters were experimentally tested and presented in this paper. This approach turned out to be successful and allowed us to predict some trends in the system and to determine the conditions of deposition of compact and high-tungsten-content CuW alloys.

The used methodology of investigation and search for new procedures allowed us to obtain the material of high tungsten content and of compact structure. As it is shown in this paper, the $\mathrm{CuW}$ deposits can exhibit various compositions, morphology, and cohesion which may result in different mechanical, corrosion, and catalytic properties of the alloys.

\section{Experimental}

In all experiments, Ag foil (99.9\%, Mennica-Metale Szlachetne S.A., Poland) was used as the substrate because of well-defined and not interfering background in both energy dispersive spectroscopy (EDS) and X-ray diffraction (XRD) measurements. The influence of the substrate material was neglected and not investigated in the present work. In fact, this parameter might influence the deposit properties, but in an insignificant way. Before the alloy deposition, the surface of the cathode was carefully polished, cleaned with a nonionic detergent, rinsed with water, dried, and weight.

Deionized water (resistivity 18.2 M $\Omega$, Millipore, MiliQ⿱一𫝀) was used in preparation of all solutions. The composition of the galvanic bath is given in Table 1. Citrate-based bath was successfully applied in the electrodeposition of high-tungstencontent alloys with an iron-group metal [7, 8, 22]. Purity of used reagents was at least of analytical grade.

In most experiments, the specially designed system with a large volume reservoir (1 1 ) and slow circulation of bath solution was used. The volume of the electrolyzer was circa 0.51 . Two anode cell sections were located symmetrically on both sides of the cathodic compartment. The size of the cathode was $1 \times 1.5 \mathrm{~cm}$. The anodes were larger: of an area circa of $5 \mathrm{~cm}^{2}$ each. To minimize possible fast degradation of the citric bath, caused by vigorous oxygen evolution at the anode surface, a separator was placed between electrodes [26]. The separators were made of glass frit of high density. The chemically inert anodes (made of titanium grid covered with ruthenium oxide) were immersed in a $0.25 \mathrm{M} \mathrm{Na}_{2} \mathrm{SO}_{4}$ anolyte. During the deposition process, the catholyte was exchanged continuously by applying a non-turbulent forced flow. This approach allowed us to stabilize $\mathrm{pH}$ and ion concentrations. The geometry of the electrolyzer remained unchanged during the experiments. Temperature during the deposition was fixed at $70{ }^{\circ} \mathrm{C}$ with $1{ }^{\circ} \mathrm{C}$ accuracy. Because of hydrogen evolution and the used setup, the solution was not additionally stirred during the experiments.

$\mathrm{pH}$ of the galvanic bath was measured at room temperature before and after each deposition. If needed, it was adjusted to the desired value by addition of $1 \mathrm{M}$ sodium hydroxide or $1 \mathrm{M}$ citric acid.

The applied current densities were in the $15-150 \mathrm{~mA} \mathrm{~cm}^{-2}$ range. An EG\&G PAR 173 A potentiostat/galvanostat was used as the power source. All the depositions were performed in the galvanostatic regime. We made sure that the declared current density was really constant. Current efficiency (CE) was calculated by dividing the theoretical electric charge necessary for the deposition of the obtained given amount of the alloy by the total charge passed. The theoretical charge was calculated by taking into account the increase in mass of cathode (weight of the deposit) and composition of the deposited alloy. The difference between the total charge passed and the charge related to the mass increase was caused by the hydrogen evolution reaction. The composition of deposits was determined in the measurements with a scanning electron microscope (SEM), Merlin (ZEISS), coupled with an EDS device, QUANTAX 400 (Bruker). A light microscope Axio Observer A1 (ZEISS) was used for color and shine determination and preliminary estimation of layer imperfections. The XRD diffraction patterns were obtained by using a X'Pert MPD Pro 
Table 1 Composition of galvanic bath used for electrodepositions. Chemicals, their roles and concentrations are listed

\begin{tabular}{lllll}
\hline Number & Name & Role & Concentration & Concentration (mM) \\
\hline 1 & Sodium tungstate dihydrate & Source of tungstate ions & $81.6 \mathrm{~g} / 1$ & 261 \\
2 & Tri-sodium citrate dihydrate & Complexing agent & $79 \mathrm{~g} / 1$ & 269 \\
3 & Boric acid & Amorphous structure promoters & $10.5 \mathrm{~g} / 1$ & 170 \\
4 & Phosphoric acid & Amorphous structure promoters & $6.1 \mathrm{ml} / 1(85 \%)$ & 89 \\
5 & Ethoxylated nonylphenol mixture & Wetting agent & $70 \mu \mathrm{l} / 1$ & \\
6 & Rokafenol N-10 & Brightening agent & $50 \mathrm{mg} / 1$ & 0.6 \\
7 & 2-Butin-1,4-diol & Source of copper ions & Various concentrations & $0.4-20$ \\
\hline
\end{tabular}

Alpha1 instrument (Philips) with a copper anode. $\mathrm{K} \alpha_{1}$ radiation of wavelength $1.540598 \AA$ was employed. X-ray photoelectron spectroscopy (XPS) measurements were done with a PHI 5000 VersaProbe instrument.

The X-Stat 2.02 (by John Murray) software was used for fractional factorial design of experiments, and the appropriate selection of the deposition conditions.

\section{Results and discussion}

In the citrate baths used in tungsten-based alloy electrodeposition, several parameters can impact the process [7, 27-30]. These parameters can be divided into two groups. The first group contains the parameters related to the bath solution. Such parameters as $\mathrm{pH}$, concentrations, and sources of deposited metal ions, other component concentrations (e.g., citrates and ammonia ions, boron, and phosphorus species, if present) and types and amounts of brighteners and wetting agents are usually taken into account. Also, mutual relations between the bath components (chemical equilibria) and bath temperature should be considered. Most likely, these parameters influence the existence and stability of different $\mathrm{W}$ species and transition metal complexes. The second group is related to the electrodeposition process: current regime (i.e., direct current or current pulses), cathodic current density, geometry of electrolyzer cell, electrode base material, and the corresponding overpotentials of the reduced ions.

All parameters listed above may be considered to get the desired properties of the deposit: elemental composition of the deposit, morphology of the layer, current efficiency (CE), mass yield of the deposition, hardness, internal structure, layer density, resistance to corrosion, and wear and appearance. In our work, we decided to focus the investigations on maximizing tungsten content, smooth morphology, and compact structure. Current efficiency (CE) was also taken into account; however, its increase did not belong to the major goals of optimization of the $\mathrm{CuW}$ plating process. Basing on our experience and the preliminary experimental data, we concluded that the following plating process parameters, current density, $\mathrm{pH}$, and copper ion concentration, are potentially the most crucial for the formation of the desired material.

The optimization was done in several consecutive steps. In the first step, the fractional factorial design of experiment was

Table 2 Full matrix of 3 arbitrary parameters, A, B and C, at their three levels, low, medium, and high

\begin{tabular}{|c|c|c|c|c|c|c|c|c|c|}
\hline & 1 & 2 & 3 & 4 & 5 & 6 & 7 & 8 & 9 \\
\hline Parameter A & Low & Low & Low & Low & Low & Low & Low & Low & Low \\
\hline Parameter B & Low & Medium & High & Low & Low & Medium & High & High & Medium \\
\hline \multirow[t]{2}{*}{ Parameter C } & Low & Low & Low & Medium & High & Medium & High & Medium & High \\
\hline & 10 & 11 & 12 & 13 & 14 & 15 & 16 & 17 & 18 \\
\hline Parameter A & Medium & Medium & Medium & Medium & Medium & Medium & Medium & Medium & Medium \\
\hline Parameter B & Low & Medium & High & Low & Low & Medium & High & High & Medium \\
\hline \multirow[t]{2}{*}{ Parameter C } & Low & Low & Low & Medium & High & Medium & High & Medium & High \\
\hline & 19 & 20 & 21 & 22 & 23 & 24 & 25 & 26 & 27 \\
\hline Parameter A & High & High & High & High & High & High & High & High & High \\
\hline Parameter B & Low & Medium & High & Low & Low & Medium & High & High & Medium \\
\hline Parameter C & Low & Low & Low & Medium & High & Medium & High & Medium & High \\
\hline
\end{tabular}

Combinations chosen for orthogonal array are italicized 
Table 3 Orthogonal array with fixed values of real parameters (A, B, and $\mathrm{C}$ ): $\mathrm{pH}$, copper ion concentration, and current density

\begin{tabular}{lccc}
\hline Number & $\mathrm{pH}$ & $C_{\mathrm{Cu}}{ }^{2+}(\mathrm{mM})$ & $-j\left(\mathrm{~mA} \mathrm{~cm}^{-2}\right)$ \\
\hline I & 7.3 & 2.0 & 15 \\
II & 7.3 & 10.0 & 75 \\
III & 7.3 & 20.0 & 150 \\
IV & 8.3 & 2.0 & 75 \\
V & 8.3 & 10.0 & 150 \\
VI & 8.3 & 20.0 & 15 \\
VII & 9.3 & 2.0 & 150 \\
VIII & 9.3 & 10.0 & 15 \\
IX & 9.3 & 20.0 & 75 \\
\hline
\end{tabular}

applied. Table 2 presents the full matrix of correlations of 3 arbitrary parameters at 3 levels which give 27 combinations. In the beginning, these arbitrary parameters were named $\mathrm{A}, \mathrm{B}$, and $\mathrm{C}$ and their possible levels were labeled as low, medium, and high. From the full matrix, an orthogonal array was picked with the use of the statistical software. This reduction of number of experiments was done with maintaining high probability of finding the extremum and possible trends. The chosen combinations of parameters are highlighted in Table 2.

In Table 3, the results of transformation of arbitrary parameters and their levels to real (experimental) parameters and real values are presented. The combinations given in Table 3 were sorted out to facilitate the experiments and to minimize the volume of wastes. Rows from I to IX in Table 3 were divided into three groups of different bath $\mathrm{pH}(7.3,8.3$, and 9.3). As it can be seen, copper ion concentration is given in ascending order within the subgroups $(2,10$, and $20 \mathrm{mM}) . \mathrm{Cu}^{2+}$ concentration was increased by adding small volumes of concentrated solution of copper sulfate. The copper loss related to the amount of deposited copper was also compensated. As parameter $\mathrm{C}$, the cathodic current density was chosen $(15,75$, $150 \mathrm{~mA} \mathrm{~cm}{ }^{-2}$ ), because this parameter is not related to the bath composition and can be easily changed in non-monotonic order. The low level was lower than the high level by one order of magnitude for both current density and $\mathrm{Cu}^{2+}$ concentration and by two orders of magnitude for activity of the hydrogen ion. All depositions were repeated twice for all 9 combinations and controlled with the method of partial repetition. From all 9 combinations, 3 combinations were twice randomly chosen and their results were compared with the previous. Deposition time was equal to $1 \mathrm{~h}$ in all cases.

The full matrix of correlation can be visualized as a cube composed of 27 subunits. The results of selected experiments are highlighted at the left part of Fig. 1 (quasi 3-D projection). A 2-D representation/compression is placed at the right hand side of Fig. 1. As it can be seen in Fig. 1, the samples vary significantly in surface morphology. Most of the samples reveal powder-like coverage with spherical objects on the surface. Although the size of the granules can vary significantly between samples I-IX, for each sample, the distribution of the spherical objects is rather uniform. Only the sample/layer deposited with medium-level current density $\left(75 \mathrm{~mA} \mathrm{~cm}^{-2}\right)$, medium $\mathrm{pH}$ (8.3), and low copper ion concentration (2 mM) exhibits a relatively smooth morphology. Also, only so deposited layer was satisfactorily adhered to the surface; it could not be repelled with a strongly adhesive scotch tape. This sample had also the highest tungsten content ( $>7$ at.\%) which distinguished it from the other layers. Depositions with the low $\mathrm{Cu}$ (II) ion concentration resulted in a very low current efficiency for all samples. All obtained compositions and CEs for combinations I-IX are given in Fig. 2.

Despite the fact that current efficiency was small, the smooth morphology and high tungsten content made us select $\mathrm{pH}$ of ca. $8.3, j=-75 \mathrm{~mA} \mathrm{~cm}^{-2}$ and $C_{\mathrm{Cu}}{ }^{2+}=2.0 \mathrm{mM}$ as the initial conditions for the next step of optimization. The $\mathrm{pH}$ optimization was omitted because of bad stability and short time of use of baths of $\mathrm{pH}$ different from 8.3. In fact, the value 8.3 was the innate value for the baths of composition given in Table 1.

In the second step of the optimization process, the alloy deposits were obtained from bath solutions containing various copper ion concentrations. Current density was fixed at

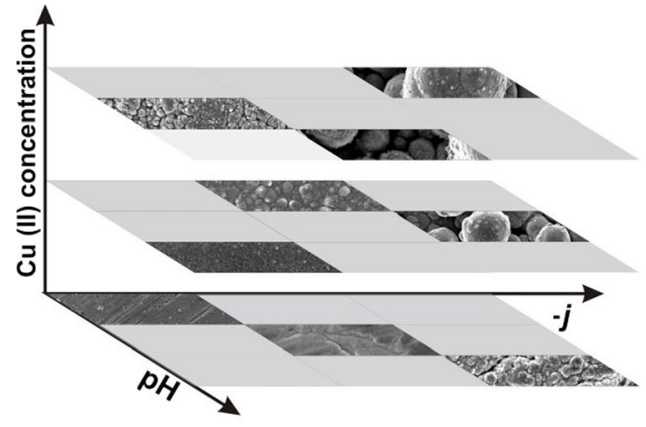

Fig. 1 Cross-section of 3D representation of full matrix of correlation (left hand side) and 2D picture of various surface morphologies obtained in the first step of optimization of electrodeposition of $\mathrm{CuW}$ system.

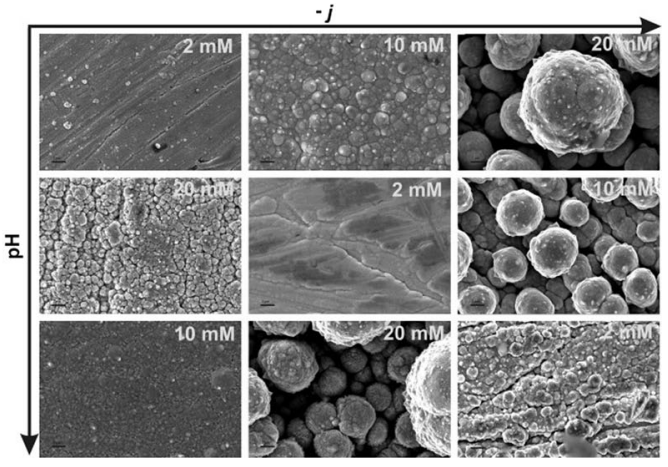

Horizontal axes represent increase of $\mathrm{pH}$ and cathodic current density. Particular copper ion concentrations are given in 2D picture. Size of each picture $20 \mu \mathrm{m} \times 30 \mu \mathrm{m}$ 


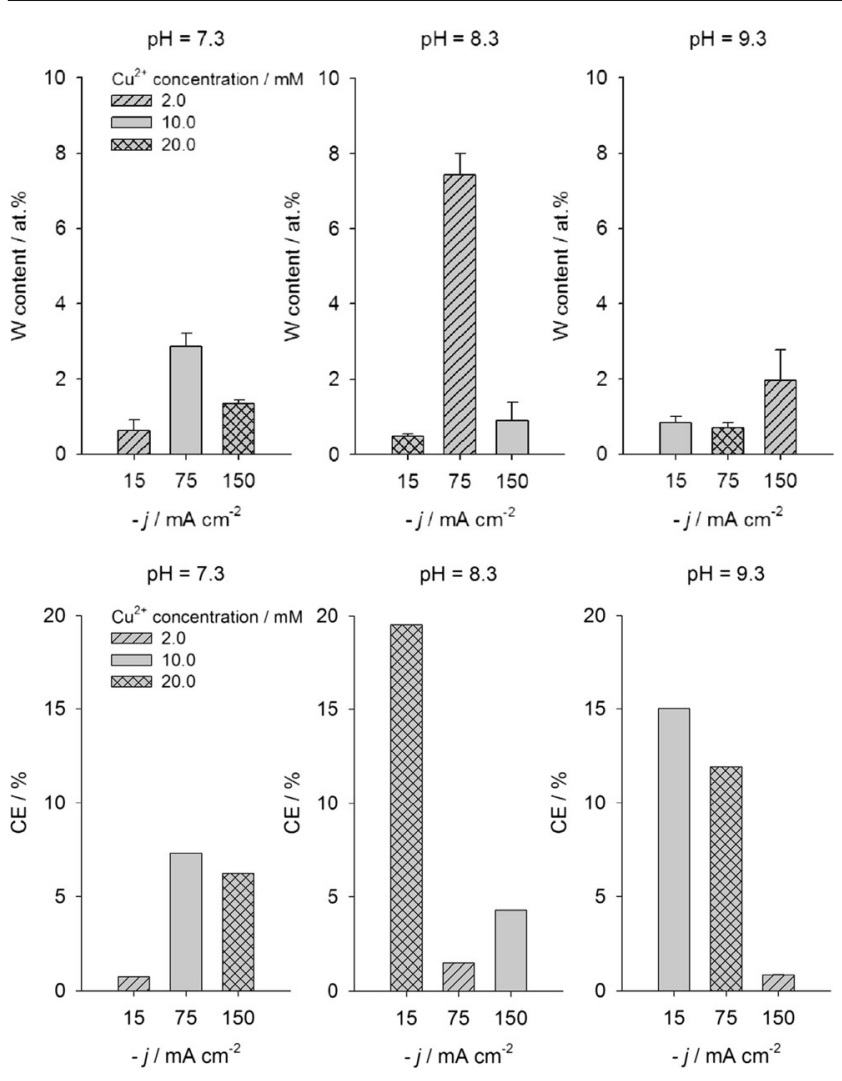

Fig. 2 Bar plots of tungsten content (top) and current efficiency (bottom) vs. cathodic current density, $-j$, for different $\mathrm{pH}$. Error symbol represents $\pm 1 \mathrm{SD}$

$-75 \mathrm{~mA} \mathrm{~cm}^{-2}$. Tungsten content in those samples was plotted vs. $C_{\mathrm{Cu}}{ }^{2+}$ in a range from 0.4 to $10.0 \mathrm{mM}$ and is presented in Fig. 3. The highest tungsten content, over 12 at.\%, was obtained for the lowest copper ion concentration $(0.4 \mathrm{mM})$; however, then the variation of the results was unacceptably high. Also, the mass gain was very low. The deposits obtained from the solutions with copper ion concentration higher than $2.0 \mathrm{mM}$ had tungsten content lower than 4 at.\% and their structure was varying.

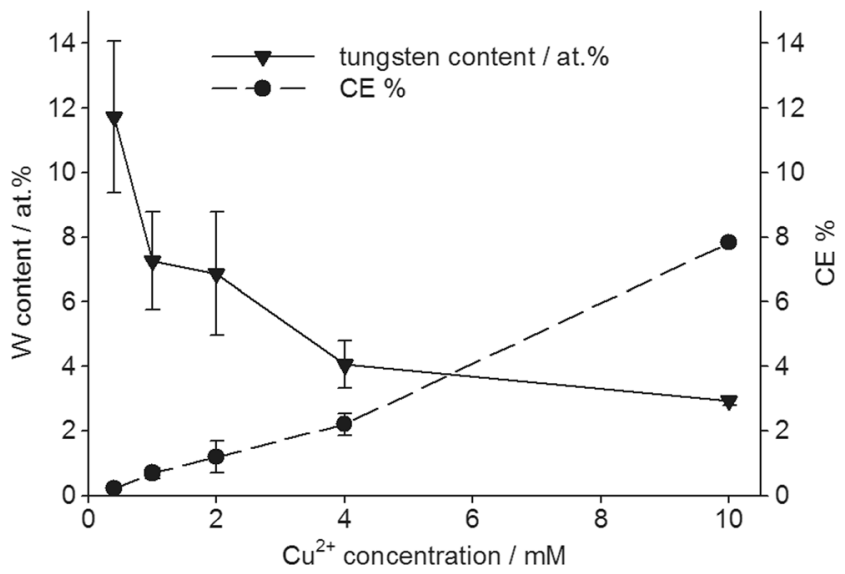

Fig. 3 Tungsten content in alloys (left axis) and current efficiency (right axis) plotted vs. copper ion concentration for $j=-75 \mathrm{~mA} \mathrm{~cm}^{-2}$ and $\mathrm{pH}=8.3$. Error symbol represents $\pm 1 \mathrm{SD}$
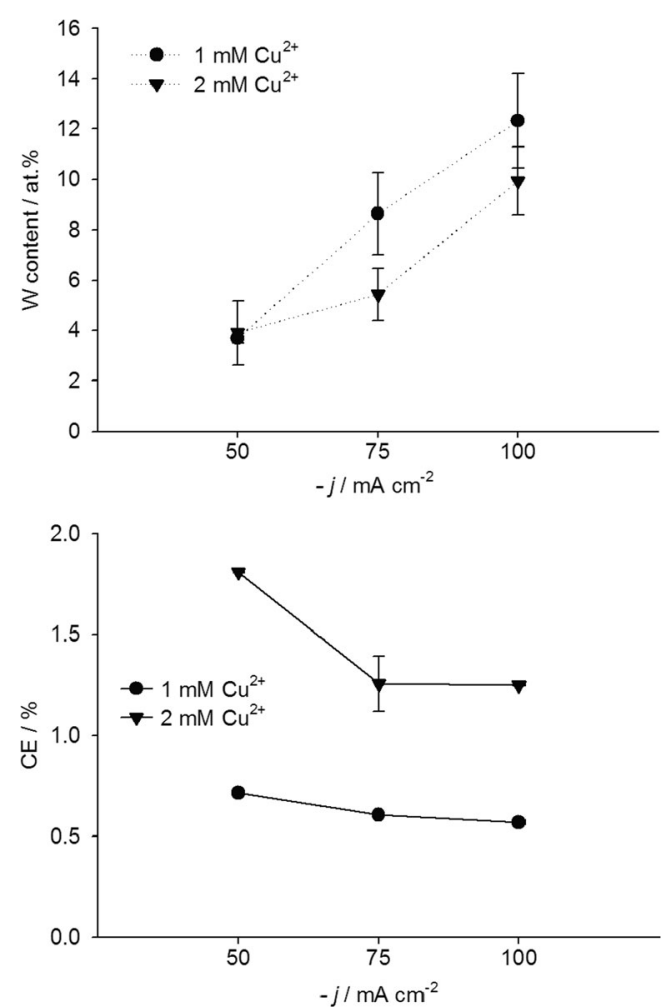

Fig. 4 Tungsten content (top) and CE (bottom) plotted vs. current density, obtained in $\mathrm{pH}=8.3$ in presence of 1.0 and $2.0 \mathrm{mM}$ copper ion. Error symbol represents $\pm 1 \mathrm{SD}$

For the third step of optimization, only two copper ion concentrations were chosen: 1.0 and $2.0 \mathrm{mM}$. In this step, the influence of cathodic current density was examined for three values: $-50,-75$, and $-100 \mathrm{~mA} \mathrm{~cm}{ }^{-2}$. The results are shown in Fig. 4. For both copper ion concentrations, the use of the lowest current density of $-50 \mathrm{~mA} \mathrm{~cm}{ }^{-2}$ resulted in a decrease in tungsten content in comparison to the value established in the first step of the optimization (ca. 7 at.\%). For this current density, the tungsten content was not affected by concentration of $\mathrm{Cu}(\mathrm{II})$ in the bath solution. With an increase in current density the tungsten content in the alloy increased for both copper ion concentrations. The surface morphology of the deposits is portrayed in Fig. 5. As it can

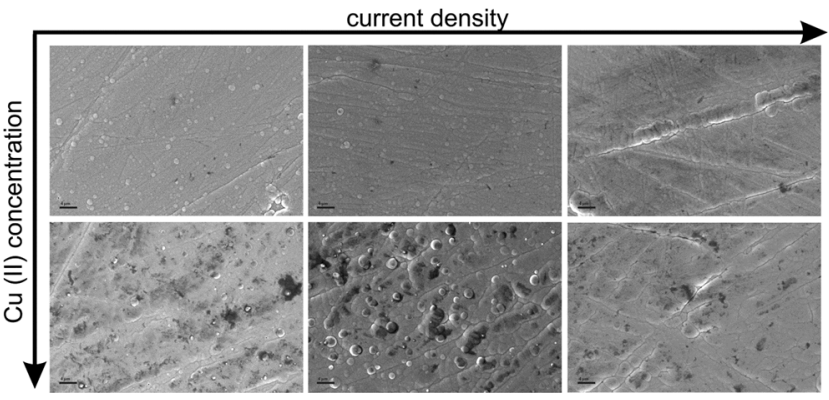

Fig. 5 Selected SEM micrographs sorted vs. absolute current density and $\mathrm{Cu}(\mathrm{II})$ concentration. Samples were electrodeposited in $\mathrm{pH}=8.3$, in presence of either 1.0 or $2.0 \mathrm{mM}$ copper ion, at current densities -50 , -75 , and $-100 \mathrm{~mA} \mathrm{~cm}^{-2}$. Size of each picture $40 \mu \mathrm{m} \times 60 \mu \mathrm{m}$ 


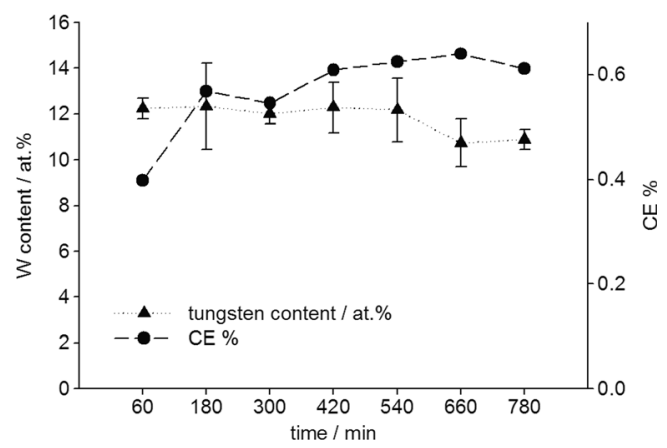

Fig. 6 Tungsten content and current efficiency plotted vs. deposition time. $\mathrm{pH}=8.3$, copper ion concentration $=1.0 \mathrm{mM}$, and $j=-100 \mathrm{~mA} \mathrm{~cm}^{-2}$. Error bar represents $\pm 1 \mathrm{SD}$

be seen, rougher surface of the deposit is related to higher copper ion concentration.

In the last step of optimization, the constancy of current efficiency and alloy composition over a long time of deposition were examined. The depositions were done under the conditions of $j=-100 \mathrm{~mA} \mathrm{~cm}^{-2}, 1.0 \mathrm{mM}$ copper ion concentration and up to $13 \mathrm{~h}$ of non-stop electrolysis. The obtained dependences are presented in Fig. 6. It is worth to emphasize that all the deposits were compact and well attached to the substrate material surface. A SEM micrograph of the typical alloy surface is shown in Fig. 7. The tungsten content was close to $30 \mathrm{wt.} \%$ (> 12 at.\%) which allowed us to rate the obtained material among hightungsten-content alloys (also called tungsten heavy alloysWHAs). The current efficiency (CE) was steady, after an initial growth, and was low $(<0.7 \%)$. The average thickness increase was approximately $1 \mu \mathrm{m} / \mathrm{h}$ which was an acceptable value.

The metallic character of both elements in the alloy (W and $\mathrm{Cu}$ ) was confirmed by the data obtained with XPS and electron diffraction spectroscopy. In the XRD diffractograms/ diffraction patterns, there was no evidence for the presence of oxide species in the alloy samples. The presence of oxygen was limited to very thin, outermost part of the deposit. In the alloy bulk, no oxygen was found. In XPS measurements

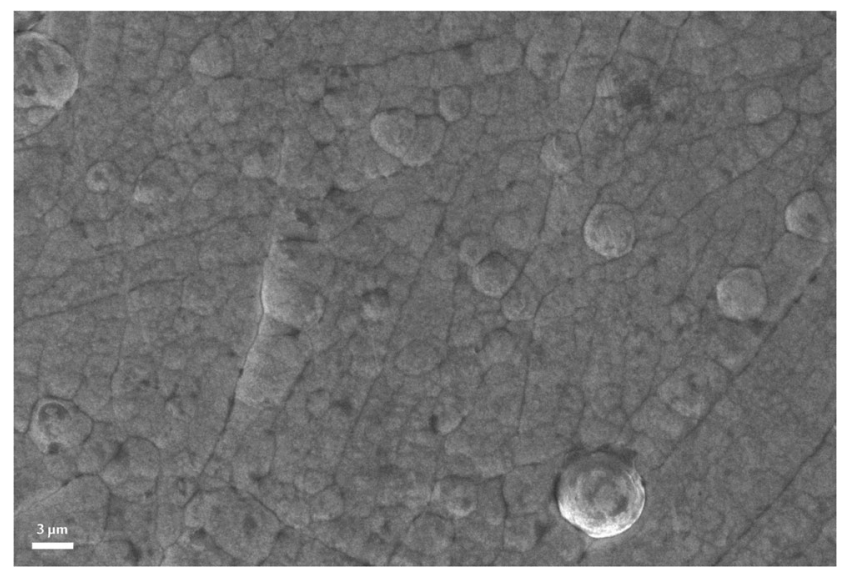

Fig. 7 SEM micrograph of typical $\mathrm{CuW}$ layer deposited in $\mathrm{pH}=8.3$, $1.0 \mathrm{mM} \mathrm{Cu}(\mathrm{II})$, and $j=-100 \mathrm{~mA} \mathrm{~cm}^{-2}$. Electrodeposition time $9 \mathrm{~h}$. Size of picture $40 \mu \mathrm{m} \times 60 \mu \mathrm{m}$

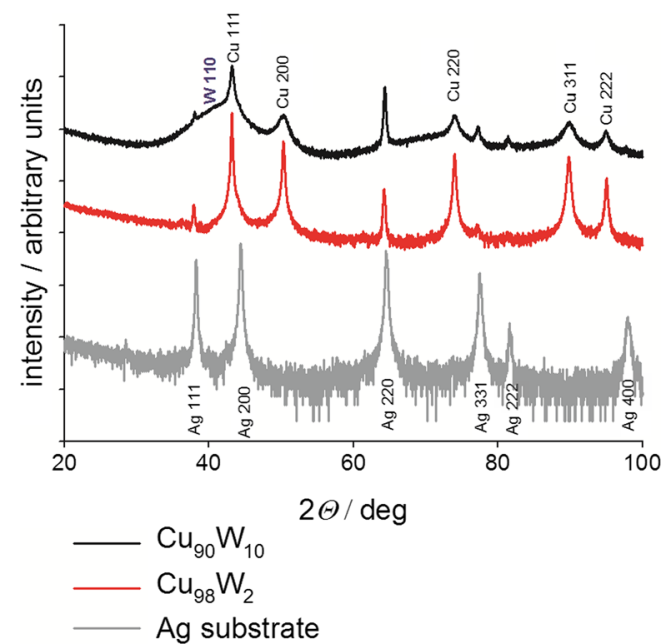

Fig. 8 X-ray diffractograms of $\mathrm{CuW}$ coverages of various content of tungsten plated on Ag substrate

coupled with Ar ion etching, oxygen was detected only up to $20-\mathrm{nm}$ depth from the alloy surface. At deeper locations, no oxygen signal was detected and the patterns obtained for $\mathrm{Cu}$ and $\mathrm{W}$ were typical of the metallic phases.

The internal structure of electrodeposited $\mathrm{CuW}$ alloy was strongly affected by the tungsten content. For small W content (up to 4 at.\%), the layer had the structure of polycrystalline copper. A typical diffractogram obtained for such material is presented in Fig. 8. The positions of the peaks in the diffractograms correspond to the positions of metallic copper; however, the peaks are slightly wider which means that the size of $\mathrm{Cu}$ crystallites is very small (in the range of hundred nanometers) or the internal stress is substantially increased. The internal stress may be caused by the incorporation of $\mathrm{W}$ into $\mathrm{Cu}$ lattice. The new structure of $\mathrm{CuW}$ alloy appeared only at a much higher $\mathrm{W}$ content (> 8 at. \%) with the first maximum at circa $40 \mathrm{deg}$. close to $\mathrm{W} 110$ and the second at circa $72 \mathrm{deg}$. (W 211). This is a strong evidence of the existence of the solid solution of $\mathrm{Cu}$ in $\mathrm{W}$. Both peaks are very wide indicating amorphous $\mathrm{CuW}$ phase. The existence of narrow peaks corresponding to hkl copper positions indicates that $\mathrm{Cu}$ nanocrystals are built into this amorphous phase. It can be concluded from the analysis of the diffractograms in Fig. 8 that the copper nanocrystals are of size circa $100 \mathrm{~nm}$ (in orientation 111) and 30-40 nm (in orientation 100) which was suggested already in [14].

\section{Conclusions}

The experiments performed indicated that the binary $\mathrm{CuW}$ heavy alloy can be electrodeposited from citrate plating baths. This bath is of very low toxicity, is easy in preparation and, in addition, the deposition design resulted in its longtime use (at least $10 \mathrm{~h}$ of continuous work without any adjustment). By 
changing the conditions/parameters of the deposition process, the properties of obtained materials could be substantially altered. In particular, deposit composition, current efficiency, and surface morphology could be changed significantly. These quantities seemed to be most affected by the combination of copper ion concentration, current density, and $\mathrm{pH}$ of the galvanic bath solution.

The alloys obtained under the following conditions: copper ion concentration of $1.0 \mathrm{mM}$, current density of $-100 \mathrm{~mA} \mathrm{~cm}{ }^{-2}$, and $\mathrm{pH}$ ca. 8.3 had a high tungsten content and smooth and uncracked morphology. These conditions can be considered as optimal and the alloy properties made us expect that this material can find a range of applications. We want to admit here that in the depositions performed so far, we could not reach a satisfying current efficiency, compared to the alloys deposited from solutions containing tungstate, molybdate, and iron-group metal cations. The structure of the electrodeposited alloy can be described as an amorphous solid solution of $\mathrm{Cu}$ in $\mathrm{W}$ with built-in $\mathrm{Cu}$ nanocrystals. The solid solution is a unique form, rather metastable, of $\mathrm{CuW}$ alloy impossible to be obtained by using the classical casting foundry method and by mechanical alloying. The $\mathrm{CuW}$ alloy does not resemble any of the iron-group metal-W alloys. Those alloys are simply based on either the $\mathrm{Ni}, \mathrm{Co}$, and Fe structures or their thermodynamically stable intermetallic compounds as, e.g., $\mathrm{Ni}_{4} \mathrm{~W}$ and $\mathrm{Co}_{3} \mathrm{~W}$ [31].

The factorial design of experiments and the following optimization experiments appeared successful in this work and valuable in the development of a new material and optimization of the corresponding electrodeposition process.

Acknowledgments This work was financed by Polish NCN Grant 2015/17/N/ST5/03352. The SEM images were obtained using the equipment purchased within CePT Project No.: POIG.02.02.00-14-024/08-00.

Open Access This article is distributed under the terms of the Creative Commons Attribution 4.0 International License (http:// creativecommons.org/licenses/by/4.0/), which permits unrestricted use, distribution, and reproduction in any medium, provided you give appropriate credit to the original author(s) and the source, provide a link to the Creative Commons license, and indicate if changes were made.

\section{References}

1. $\mathrm{Lu} \mathrm{K}(2010)$ The future of metals. Science 328:319-320

2. Akihisa I (2000) Stabilization of metallic supercooled liquid and bulk amorphous alloys. Acta Mater 48:279-306

3. Schuh CA, Hufnagel TC, Ramamurty U (2007) Mechanical behavior of amorphous alloys. Acta Mater 55:4067-4109

4. Landolt D (2002) Electrodeposition science and technology in the last quarter of the twentieth century. J Electrochem Soc 149:S9-S20
5. Sham-Diamand Y, Sverdlov Y (2000) Electrochemically deposited thin film alloys for ULSI and MEMS applications. Microelectron Eng 50:525-531

6. Gupta M, Podlaha EJ (2010) Electrodeposition of CuNiW alloys: thin films, nanostructured multilayers and nanowires. J Appl Electrochem 40:1429-1439

7. Tsyntsaru N, Cesiulis H, Donten M, Sort J, Pellicer E, PodlahaMurphy EJ (2012) Modern trends in tungsten alloys electrodeposition with iron group metals. Surf Eng Appl Electrochem 48:491520

8. Donten M, Cesiulis H, Stojek Z (2000) Electrodeposition and properties of Ni-W, Fe-W and Fe-Ni-W amorphous alloys. A comparative study. Electrochim Acta 45:3389-3396

9. Sun S, Bairachna T, Podlaha EJ (2013) Induced codeposition behavior of electrodeposited NiMoW alloys. J Electrochem Soc 160: D434-D440

10. Brenner A (1963) Electrodeposition of alloys principles and practice. ACADEMIC PRESS, New York and London

11. Clark WE, Lietzke MH (1952) The mechanism of the tungsten alloy plating process. J Electrochem Soc 99:245-249

12. Eliaz N, Gileadi E (2007) The mechanism of induced codeposition of Ni-W alloys. ECS Trans 2:337-349

13. Indyka P, Beltowska-Lehman E, Tarkowski L, Bigos A, GarcíaLecina E (2014) Structure characterization of nanocrystalline NiW alloys obtained by electrodeposition. J Alloys Compd 590:75-79

14. Bacal P, Indyka P, Stojek Z, Donten M (2015) Unusual example of induced codeposition of tungsten. Galvanic formation of $\mathrm{Cu}-\mathrm{W}$ alloy. Electrochem Commun 54:28-31

15. Subramanian P.R., Laughlin D.E. (1991) Indian Institute of Metals.In: Nagender Najdu SV, Rama Rao P (ed). Calcuta, 76-79

16. Kola A, Geng X, Podlaha EJ (2016) Ag-W electrodeposits with high $\mathrm{W}$ content from thiourea-citrate electrolytes. J Electroanal Chem 761:125-130

17. Kazimierczak H, Ozga P, Socha RP (2013) Investigation of electrochemical co-deposition of zinc and molybdenum from citrate solutions. Electrochim Acta 104:378-390

18. Gotou M, Arakawa T, Watanabe N, Hara T, Tomita T, Hashimoto A, Takanashi H, Koiwa I (2014) Copper-molybdenum source ratio and complexing agent for high molybdenum content in electrodeposited $\mathrm{Cu}-\mathrm{Mo}$ electrochemical/electroless deposition. J Electrochem Soc 161:D628-D631

19. Vasko AT (1969) Wolframa Elektrohimija. Tehnika, Kiev in Russian

20. Clark WE, Holt ML (1948) Electrodeposition of cobalt-tungsten alloys from a citrate bath. J Electrochem Soc 94:244-252

21. Cesiulis H, Baltutiene A, Donten M, Donten ML, Stojek Z (2002) Increase in rate of electrodeposition and in $\mathrm{Ni}(\mathrm{II})$ concentration in the bath as a way to control grain size of amorphous/nanocrystalline Ni-W alloys. J Solid State Electrochem 6:237-244

22. Donten M, Stojek Z (1994) An improved bath composition for electroplating of the amorphous cobalt-tungsten alloys. Pol J Chem 68:1193-1197

23. Sridhar TM, Eliaz N, Gileadi E (2005) Electroplating of Ni4W. Electrochem Solid-State Lett 8:C58-C61

24. Mizushima I, Tang PT, Hansen HN, Somers MAJ (2005) Development of a new electroplating process for Ni-W alloy deposits. Electrochim Acta 51:888-896

25. Cesiulis H, Donten M, Donten ML, Stojek Z (2001) Electrodeposition of $\mathrm{Ni}-\mathrm{W}, \mathrm{Ni}-\mathrm{Mo}$ and $\mathrm{Ni}-\mathrm{Mo}-\mathrm{W}$ alloys from pyrophosphate baths. Mater Sci-Medzg 7:237-241

26. Donten M, Osteryoung J (1991) Electrochemical and chemical reactions in baths for plating amorphous alloys. J Appl Electrochem 21:496-503

27. Plieth W (2011) Electrocrystallization-factors influencing structure. J Solid State Electrochem 15:1417-1423 
28. Zakharov EN, Gamburg YD, Goryunov GE, Lyakhov BF (2006) Effect of cations of alkali metals and ammonium on the process of deposition and structure of iron-tungsten alloys. Russ J Electrochem 42:895-900

29. Tsyntsaru N, Bobanova J, Ye X, Cesiulis H, Dikusar A, Prosycevas I (2009) Iron tungsten alloys electrodeposited under direct current from citrate-ammonia plating baths. Surf Coat Technol 203:3136-3141
30. Younes O, Gileadi E (2000) Electroplating of high tungsten content Ni/W alloys. Electrochem Solid State Lett 3:543545

31. Donten M (1999) Bulk and surface composition, amorphous structure, and thermocrystallization of electrodeposited alloys of tungsten with iron, nickel, and cobalt. J Solid State Electrochem 3:87-96 